\title{
Antimicrobial activity of marigold (Tagetes erecta), mulberry (Morus indica), and red shallot (Allium ascalonicum) extracts against Streptococcus agalactiae
}

\author{
Tanawadee Mekvimol ${ }^{1}$, Gannika Poonthong ${ }^{1}$, Chayanit Chaipunna ${ }^{1}$ and Natapol Pumipuntu ${ }^{1,2}$
}

1. One Health Research Unit, Faculty of Veterinary Sciences, Mahasarakham University, Maha Sarakham 44000, Thailand; 2. Office of Academic Affairs, Faculty of Veterinary Sciences, Mahasarakham University, Maha Sarakham 44000, Thailand. Corresponding author: Natapol Pumipuntu, e-mail: natapol.p@msu.ac.th

Co-authors: TM: stamptana@gmail.com, GP: seal_ding@hotmail.com, CC: cchaipunna@gmail.com Received: 11-02-2020, Accepted: 13-04-2020, Published online: 12-05-2020

doi: www.doi.org/10.14202/IJOH.2020.56-60 How to cite this article: Mekvimol T, Poonthong G, Chaipunna C, Pumipuntu N (2020) Antimicrobial activity of marigold (Tagetes erecta), mulberry (Morus indica), and red shallot (Allium ascalonicum) extracts against Streptococcus agalactiae, Int. J. One Health, 6(1): 56-60.

\begin{abstract}
Background and Aim: The increasing antimicrobial resistance with reduced susceptibility to antimicrobial drugs is becoming a major concern for both human and animal, which raises health morbidity and mortality rate of cases that cannot be treated by antibiotics. Nowadays, there are many efforts to minimize the misuse of antibiotics. This study evaluated the antimicrobial activity of the crude ethanolic extracts of three Thai herbs divided in four groups; petals of marigold (Tagetes erecta), mulberry leaves and root barks (Morus indica), and whole onions of red shallot (Allium ascalonicum) against Streptococcus agalactiae.

Materials and Methods: The antimicrobial activity of four groups of the crude extracts using absolute ethanol from three Thai herbs was tested against standard strains of $S$. agalactiae using the agar well diffusion method. The commercial antibiotics ceftriaxone and erythromycin were used as positive control standards to determine the sensitivity of $S$. agalactiae.
\end{abstract}

Results: The result showed that all four groups of Thai herbal extract had inhibitory activity against standard strains of $S$. agalactiae. The inhibitory concentration test values were obtained using the dilution test at 25,50, and $75 \mathrm{mg} / \mathrm{ml}$. The maximum antimicrobial activity against $S$. agalactiae was observed in the ethanolic extracts from red shallot extract, followed by leaves of mulberry, petals of marigold, and root barks of mulberry, respectively.

Conclusion: The results demonstrated that the crude extract of three Thai herbs had antimicrobial activity inhibiting the growth of $S$. agalactiae and suggesting that they may be useful in the treatment of $S$. agalactiae infections in humans and animals.

Keywords: antimicrobial activity, ethanol extract, Streptococcus agalactiae, Thai herbal extracts.

\section{Introduction}

Streptococcus agalactiae is a Gram-positive bacteria, which is classified in Group B streptococcus. It can be found as microbiota in the gastrointestinal tract of both humans and animals, especially in female animals [1]. It is usually associated with many infective diseases of neonatal animals such as meningitis and septicemia after pregnant animals have experienced traumatic damage during parturition. Moreover, it also causes a significant veterinary problem since $S$. agalactiae is recognized as the main bacterial pathogen of bovine mastitis in dairy cows by infecting the mammary glands of ruminants [2-4]. The prevalence of S. agalactiae infection in dairy cattle mastitis is different at different study sites. The previous surveillance in Chiang Mai Province, Thailand, in 2014 [5],

Copyright: Mekvimol, et al. This article is an open access article distributed under the terms of the Creative Commons Attribution 4.0 International License (http://creativecommons.org/licenses/ by/4.0/), which permits unrestricted use, distribution, and reproduction in any medium, provided you give appropriate credit to the original author(s) and the source, provide a link to the Creative Commons license, and indicate if changes were made. The Creative Commons Public Domain Dedication waiver (http:// creativecommons.org/ publicdomain/zero/1.0/) applies to the data made available in this article, unless otherwise stated. isolated the bacteria from $7.1 \%$ of bovine mastitis cases. Furthermore, it has been reported that S. agalactiae infection was prevalent in bovine mastitis cases in Columbia during 2017, where S. agalactiae infection in the dairy herds was assessed as 11-60\% and estimated as 35\% in each individual cow [6]. At present, increasing antimicrobial resistance (AMR) (including that of $S$. agalactiae) with reduced susceptibility to antimicrobial drugs is becoming a major concern for both human and animal health, not only because of the high prevalence of infections caused by this bacterial pathogen but also because of the high rate of AMR has increased and could result in economic damage or breakdown the health system, and raise morbidity and mortality rate of cases that cannot be treated by antimicrobial drugs. S. agalactiae isolated from subclinical bovine mastitis, which resistant to pirlimycin, penicillin, ampicillin, ceftiofur, cephalothin, oxacillin, sulfadimethoxine, tetracycline, and erythromycin was reported previously [7].

Nowadays, there are many efforts to minimize the misuse of antibiotics. With this intent, many researchers are looking for herbal products to use as an alternative treatment against bacterial pathogens. There have 
been studies on the antimicrobial activity of different herbal extracts against $S$. agalactiae in many previous researches, for example, Aristolochia debilis [8], Panax ginseng [8], Spatholobus suberectus [8], Moringa oleifera [9], Persea americana Mill. [10], Papaver macrostomum [11], Papaver dubium [11], Papaver argemone [11], Papaver bracteatum [11], Papaver armeniacus microstigma [11], Papaver chelidonium folium [11], Anredera diffusa [11], Cestrum auriculatum [11], Krameria triandra [11], Sambucus peruviana [11], and Xanthium strumarium [12]. Some previous studies found that red shallots contain quercetin, which has an ability to inhibit the growth of the bacteria by destroying its cell walls and membranes [13]. Herbal extracts of the root and leaves of mulberry were found to inhibit both Grampositive and Gram-negative bacteria. Interestingly, it is the leaves that contain the most active ingredient, quercetin substance [14], which is known to be effective against both Gram-positive and Gramnegative bacteria $[15,16]$. Quercetin can destroy membranes of bacteria resulting in inhibition of their growth [17]. The previous studies have revealed that marigold petal (Tagetes erecta) has many flavonoids, including patulitrin, which are substrates with antimicrobial activity that effectively to kill bacterial pathogens $[18,19]$. Furthermore, some studies have reported that both leaves and root of white mulberry extracts can also inhibit Gram-positive and Gramnegative bacteria, including Bacillus cereus, Bacillus subtilis, Staphylococcus aureus, Escherichia coli, Pseudomonas aeruginosa, Serratia marcescens, and Agrobacterium tumefaciens [20-23].

Thus, this study aims to evaluate the antimicrobial activity of the crude ethanolic extracts of three Thai herbs - marigold (T. erecta), mulberry leaves and root (Morus indica), and red shallot (Allium ascalonicum) against $S$. agalactiae for the intention to be used in the replacement of the antimicrobial drug in the future and also to reduce the problem of AMR.

\section{Materials and Methods}

\section{Ethical approval}

There is no need of the ethical approval for this study. All procedures in this study did not harm animals or humans. All experiments were done at the Veterinary Public Health Laboratory, Faculty of Veterinary Sciences, Mahasarakham University, Thailand.

\section{Herbal materials}

All plants were collected in Maha Sarakham Province, Northeast Thailand. The ethanolic extracts were made from three Thai herbs, as shown in Table-1 and their antimicrobial activity determined. The herbs selected were marigold petal ( $T$. erecta), red shallot (A. ascalonicum) leaves, and root of mulberry (M. indica), as shown in Figure-1. The weight used was recorded for each herb to compare dry matter and weight of the herbal crude extraction. Herbs were
Table-1: Thai herbal plants and their part used.

\begin{tabular}{lll}
\hline \multicolumn{2}{c}{ Herbal plants } & Part used \\
\cline { 1 - 2 } Common name & Scientific name & \\
\hline Marigold & Tagetes erecta & Petals \\
Mulberry & Morus indica & $\begin{array}{l}\text { Leaves } \\
\text { Root barks }\end{array}$ \\
Red shallot & Allium ascalonicum & Whole onions \\
\hline
\end{tabular}

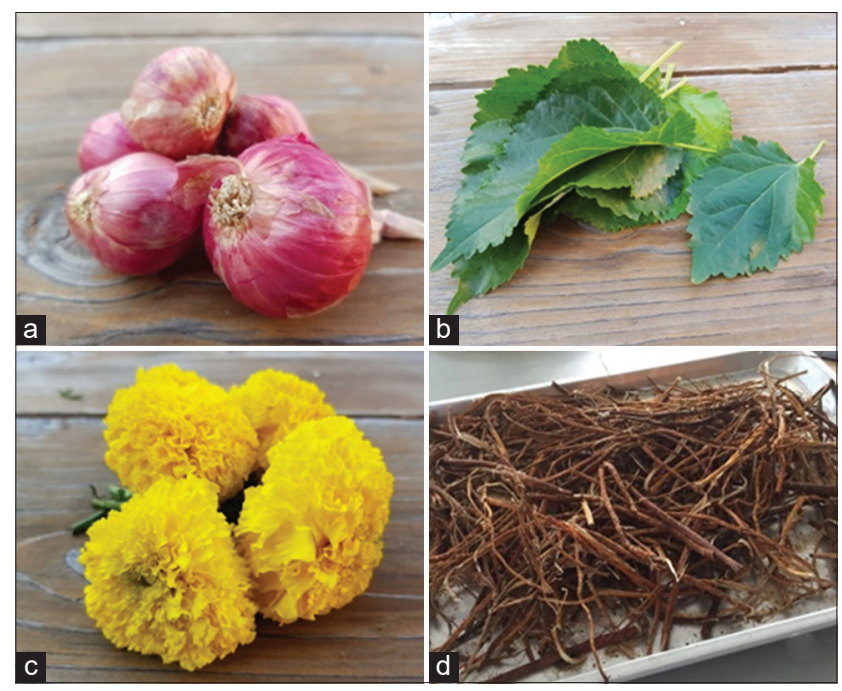

Figure-1: Pictures of Thai herbs divided into four groups: (a) red shallot (whole onions), (b) mulberry (leaves), (c) marigold (petals), (d) mulberry (root barks).

washed carefully with tap water followed by distilled water, dried at room temperature, cut into $1 \mathrm{~cm} \times 1 \mathrm{~cm}$ pieces and dried to constant weight in a hot air oven at $65^{\circ} \mathrm{C}$ for $24 \mathrm{~h}$. The dried materials were macerated and extracted with absolute ethanol in ratio of 1:5 for $24 \mathrm{~h}$ at room temperature. The herb extracts were filtered and concentrated to dryness by evaporation in a rotary vacuum evaporator at $60 \mathrm{rpm}, 289 \mathrm{mbar}$ and $65^{\circ} \mathrm{C}$ in a water bath to yield the crude ethanol extracts, which were used for further antimicrobial tests. The weight of all extracts was recorded. Crude extracts were dissolved in absolute ethanol as solvent. The crude herbal extracts were used at concentrations of 25,50 , and $75 \mathrm{mg} / \mathrm{mL}$.

\section{Test bacterial culture}

A standard strain of S. agalactiae (DMST1729) was tested for the antimicrobial susceptibility and resistance by disk diffusion procedure. S. agalactiae was inoculated on Tryptone Soya Agar (Oxoid, Basingstoke, UK) in aerobic conditions and incubated at $37^{\circ} \mathrm{C}$ for $24 \mathrm{~h}$. Antimicrobial activity tests involved direct colony suspension following CLSI guidelines 2016 guideline [24]. The culture colonies which had grown overnight were suspended in sterile normal saline solution at $0.85 \%$ and the turbidity of the suspensions adjusted to $0.5 \mathrm{McF}$ arland standard.

\section{Antimicrobial activity assay}

The suspensions were spread on Mueller-Hinton agar (Oxoid, Basingstoke, UK) 3 times, rotating the plate about 60 degrees each time. Each herbal extract 
stock solution was prepared at 25,50 , and $75 \mathrm{mg} / \mathrm{mL}$ in absolute ethanol and $5 \mu 1$ added to holes in plates, on which the bacteria had been grown to obtain the series concentrations, as shown in Figure-2. Two antimicrobial disks, which were used as a positive control; ceftriaxone and erythromycin (Oxoid, Basingstoke, UK) were set on the Mueller-Hinton agar and incubated in aerobic conditions at $35^{\circ} \mathrm{C}$ for $24 \mathrm{~h}$. Absolute ethanol was used as a negative control. The diameter of inhibition zone was interpreted following CLSI 2016 guideline [24].

\section{Results}

The results of the antimicrobial activity against $S$. agalactiae of the ethanol extract of various parts of the herbs are shown in Table-2. According to the zone of inhibition produced by minimal concentration $(25 \mathrm{mg} / \mathrm{ml})$, the mean diameter of the clear zone of inhibition for red shallot, mulberry leaves, mulberry root, and marigold petal extract was $12.5 \mathrm{~mm}, 9 \mathrm{~mm}$,

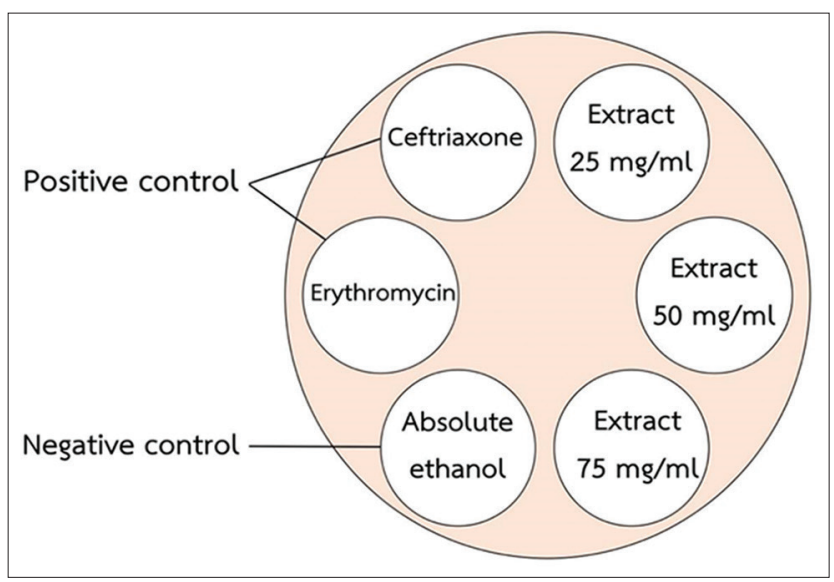

Figure-2: Position of each herbal extract stock solution, positive control, and negative control on Mueller-Hinton agar.

Table-2: Antimicrobial activity of Thai herbal extracts by measuring the zone of inhibition diameter.

\begin{tabular}{lccc}
\hline \multirow{2}{*}{$\begin{array}{l}\text { Thai herbal } \\
\text { extracts }\end{array}$} & \multicolumn{3}{c}{ Zone of inhibition diameter $\mathbf{( m m )}$} \\
\cline { 2 - 4 } & \multicolumn{3}{c}{$\begin{array}{c}\text { Herbal extracts concentration } \\
\text { ( } \mathbf{m g} / \mathbf{m l})\end{array}$} \\
\cline { 2 - 4 } & $\mathbf{2 5}$ & $\mathbf{5 0}$ & $\mathbf{7 5}$ \\
\hline Red shallot & 12.5 & 13.5 & 14 \\
& 13 & 15 & 16 \\
Mean & 12 & 13 & 14 \\
Mulberry (leaves) & 12.5 & 13.83 & 14.67 \\
& 11 & 11 & 14 \\
Mean & 8 & 10 & 11 \\
Mulberry (root bark) & 8 & 12 & 12.5 \\
& 9 & 11 & 12.5 \\
Mean & 7 & 9 & 9.5 \\
Marigold & 7 & 8 & 8.5 \\
& 7.33 & 8 & 8.5 \\
Mean & 8 & 8.33 & 8.83 \\
& 8 & 10 & 12.5 \\
\hline
\end{tabular}

$7.33 \mathrm{~mm}$, and $7.67 \mathrm{~mm}$, respectively. At medium concentration $(50 \mathrm{mg} / \mathrm{ml})$, the clear zone was $13.83 \mathrm{~mm}$, $11 \mathrm{~mm}, 8.33 \mathrm{~mm}$, and $9.5 \mathrm{~mm}$, respectively, and at the maximum concentration $(75 \mathrm{mg} / \mathrm{ml}) 14.67 \mathrm{~mm}$, $12.5 \mathrm{~mm}, 8.83 \mathrm{~mm}$, and $12 \mathrm{~mm}$, respectively.

All the herb extracts showed antimicrobial activity against $S$. agalactiae. The extracts of red shallot showed the most potent activity followed by mulberry leaves and marigold petal extracts, respectively. The ethanolic extracts of mulberry roots were found that they had the least potential activity against $S$. agalactiae. The clear zones of inhibition produced by ceftriaxone and erythromycin positive controls were $24.42 \mathrm{~mm}$ and $15.67 \mathrm{~mm}$, respectively, much higher than all the herbal extracts used in this study. There were no statistically significant differences in the antibacterial activity against $S$. agalactiae among four groups of these Thai herbal extracts in this study when tested by single-factor ANOVA.

\section{Discussion}

From the results of the antimicrobial activity of four ethanolic herbal extracts against $S$. agalactiae, the ethanolic crude extract of red shallot and mulberry leaves showed the most reasonable and potential inhibitory activity against $S$. agalactiae. We found that these Thai herbal extracts have a high potential to inhibit bacterial growth in all concentrations. These results agree with the previous reports that flavonoid compounds in red shallot can inhibit the growth of bacteria [25]. The most active flavonoid substance that can inhibit bacterial growth is quercetin, which acts by disrupting the membranes of bacteria [25]. Mozin and team studied the antimicrobial inhibition of the growth of several bacterial pathogens, including Lactobacillus spp., E. coli, and Salmonella spp. using ethanolic $(99 \%)$ or aqueous extracts of red shallot. The bioactivity compound of these Thai herbal extracts, especially for red shallot and mulberry leaves, which brought out the antimicrobial activity, seemed to have advantageous and specific activity against $S$. agalactiae. The result of this study possibly verifies the previous studies of the antimicrobial activity of plant extracts [26-28].

Our finding supported to a suggestion from a previous study which found that mulberry, red shallot, and marigold ethanolic extracts have the antimicrobial activity against many bacterial pathogens. The mulberry leaf ethanolic extract revealed to have the bacteriostatic effect against $P$. aeruginosa, Salmonella Typhi and it had the bactericidal effect toward E. coli and $S$. aureus [29]. In addition, it showed remarkable effects on the biofilm inhibition to those bacterial pathogens [29]. The red shallot extract was revealed that it could be used as an effective medicine to treat dermatomycosis and other bacterial infections such as S. aureus, B. subtilis, E. coli, and Salmonella Typhi as well as an effective antimicrobial agent which can be used as a natural food preservative and natural topical 
ointment to cure skin infections [30]. Likewise, the extract of marigold can be considered as a natural product which has a significant antibacterial effect to inhibit the growth of pathogenic bacteria such as E. coli, B. cereus, and S. aureus [31].

The investigation of the antimicrobial activity of Thai herbal extracts is an essential step toward alternative treatment strategies replacing the use of antimicrobial drugs for the antimicrobial activity against $S$. agalactiae. S. agalactiae is mentioned as one of the leading bacterial causes of invasive infections in many human and animal diseases including bacteremia, pneumonia meningitis, septicemia, urinary tract infection, skin infection, and soft-tissue infection [32] and also recognized as a major cause of mastitis pathogen in dairy cows which lead to the economic loss for the industry [33].

\section{Conclusion}

This present study and the result revealed that the antimicrobial activity of the ethanolic herbal extracts of marigold, mulberry, and red shallot could inhibit the growth of $S$. agalactiae and suggests that they can be used as the alternative treatment of $S$. agalactiae infections in human and animal. Leaf extract of mulberry was found to be the most effective against $S$. agalactiae culture. The future prospects of this study are to analyze the active ingredients and purified compounds for drug validation or to determine the suitable concentrations to use, test the in vivo experiment, and apply them as medicinal products for medical and veterinary use.

\section{Authors' Contributions}

TM, GP, CC, and NP: Schemed and designed experiment. TM, GP, and CC: Sampling and interpretation of the results. All authors analyzed the data and wrote the manuscript. NP consulted the manuscript preparation (as supervisor). All authors read and approved the final manuscript.

\section{Acknowledgments}

The research project was financially supported by Mahasarakham University (Fast Track 2020), Thailand, Grant number: 6307018. The authors are grateful to the Faculty of Veterinary Sciences, Mahasarakham University, for allowing us to use the laboratory to carry out this experiment. The authors would like to thank Asst. Prof. Dr. Prasoborn Rinthong, Pharm D, Faculty of Pharmacy, Mahasarakham University, for her advice. We also thank Miss Supaksiri Wimonsrinarachai, Faculty of Dentistry, Khon Kaen University, Thailand, for picture design.

\section{Competing Interests}

The authors declare that they have no competing interests.

\section{Publisher's Note}

Veterinary World (Publisher of International Journal of One Health) remains neutral with regard to jurisdictional claims in published institutional affiliation.

\section{References}

1. Shabayek, S. and Spellerberg, B. (2018) Group B streptococcal colonization, molecular characteristics, and epidemiology. Front. Microbiol., 9: 437.

2. Gillespie, B.E. and Oliver, S.P. (2005) Simultaneous detection of mastitis pathogens, Staphylococcus aureus, Streptococcus uberis, and Streptococcus agalactiae by multiplex real-time polymerase chain reaction. J. Dairy Sci., 88(10): 3510-3518.

3. Morach, M., Stephan, R., Schmitt, S., Ewers, C., Zschöck, M., Reyes-Velez, J., Gilli, U., Crespo-Ortiz, M.D.P., Crumlish, M., Gunturu, R., Daubenberger, C.A., Ip, M., Regli, W. and Johler, S. (2018) Population structure and virulence gene profiles of Streptococcus agalactiae collected from different hosts worldwide. Eur. J. Clin. Microbiol. Infect. Dis., 37(3): 527-536.

4. Rajagopal, L. (2009) Understanding the regulation of group B streptococcal virulence factors. Future Microbiol., 4(2): 201-221.

5. Leelahapongsathon, K., Schukken, Y.H. and Suriyasathaporn, W. (2014) Quarter, cow, and farm risk factors for intramammary infections with major pathogens relative to minor pathogens in Thai dairy cow. Trop. Anim. Health Prod., 46(6): 1067-1078.

6. Reyes, J., Chaffer, M., Rodriguez-Lecompte, J.C., Sánchez, J., Zadoks, R.N., Robinson, N., Cardona, X., Ramírez, N. and Keefe, G.P. (2017) Short communication: Molecular epidemiology of Streptococcus agalactiae differs between countries. J. Dairy Sci., 100(11): 9294-9297.

7. Tomazi, T., de Souza Filho, A.F., Heinemann, M.B. and Santos, M.V.D. (2018) Molecular characterization and antimicrobial susceptibility pattern of Streptococcus agalactiae isolated from clinical mastitis in dairy cattle. PLoS One, 13(6): e0199561.

8. Guo, W.L., Deng, H.W., Wang, F., Wang, S.F., Zhong, Z.H., Sun, Y., Chen, X.F., Wang, J.H. and Zhou, Y.C. (2019) In vitro and in vivo screening of herbal extracts against Streptococcus agalactiae in Nile tilapia (Oreochromis niloticus). Aquaculture, 503: 412-421.

9. Kamble, M., Gallardo, W., Yakupitiyage, A., Chavan, B., Rusydi, R. and Rahma, A. (2014) Antimicrobial activity of bioactive herbal extracts against Streptococcus agalactiae biotype 2. Int. J. Basic Appl. Biol., 2(3): 152-155.

10. Cardoso, P., Scarpassa, J., Pretto-Giordano, L., Otaguiri, E., Yamada-Ogatta, S., Nakazato, G., Perugini, M., Moreira, I. and Vilas-Boas, G. (2016) Antibacterial activity of avocado extracts (Persea americana Mill.) against Streptococcus agalactiae. Phyton, 85(1): 218-24.

11. Delfani, S., Bahmani, M., MohammadrezaeiKhorramabadi, R. and Rafieian-Kopaei, M. (2017) Phytotherapy in Streptococcus agalactiae: An overview of the medicinal plants effective against Streptococcus agalactiae. J. Clin. Diagn. Res., 11(6): DE01-DE2.

12. Regassa, F. and Wubie, M. (2015) The in-vitro antibacterial effect of three selected plant extracts against Staphylococcus aureus and Streptococcus agalactiae isolated from bovine mastitis. J. Vet. Sci. Technol., S13(1): 2-7.

13. Fattorusso, E., Iorizzi, M., Lanzotti, V. and TaglialatelaScafati, O. (2002) Chemical composition of shallot (Allium ascalonicum Hort.). J. Agric. Food Chem., 50(20): 5686-5690.

14. Enkhmaa, B., Shiwaku, K., Katsube, T., Kitajima, T., Anuurad, E., Yamasaki, M. and Yosuke, Y. (2005) Mulberry (Morus alba L.) leaves and their major flavonol quercetin 3-(6-Malonylglucoside) attenuate atherosclerotic lesion development in LDL receptor-deficient mice. J. Nutr., 135(4): 729-734.

15. Salem, M., Aly, H., Gohar, Y. and El-Sayed, A. (2013) 
Biological activity of extracts from Morus alba L., Albizzia lebbeck (L.) Benth and Casuarina glauca Sieber against the growth of some pathogenic bacteria. Int. J. Agric. Food Sci. Technol., 2(1): 9-22.

16. Grajek, K., Wawro, A. and Kokocha, D. (2015) Bioactivity of Morus alba L. extracts an overview. Int. J. Pharm. Sci. Res., 6(8): 3110-3122.

17. Wang, S., Yao, J., Zhou, B., Yang, J., Chaudry, M.T., Wang, M., Xiao, F., Li, Y. and Yin, W. (2018) Bacteriostatic effect of quercetin as an antibiotic alternative in vivo and its antibacterial mechanism in vitro. J. Food Prot., 81(1): 68-78.

18. Dasgupta, N., Ranjan, S., Saha, P., Jain, R., Malhotra, S. and Saleh, M.A. (2012) Antibacterial activity of leaf extract of Mexican marigold (Tagetes erecta) against different gram positive and gram negative bacterial strains. J. Pharm. Res., 5(8): 4201-4203.

19. Rhama, S. and Madhavan, S. (2011) Antibacterial activity of the flavonoid, patulitrin isolated from flowers of Tagetes erecta L. Int. J. Pharm. Tech. Res., 3(3): 1407-1409.

20. Thabti, I., Elfalleh, W., Tlili, N., Ziadi, M., Campos, M.G. and Ferchichi, A. (2014) Phenols, flavonoids, and antioxidant and antibacterial activity of leaves and stem bark of Morus species. Int. J. Food Properties, 17(4): 842-854.

21. Wang, W., Zu, Y., Fu, Y. and Efferth, T. (2012) In vitro antioxidant and antimicrobial activity of extracts from Morus alba L. leaves, stems and fruits. Am. J. Chin. Med., 40(2): 349-356.

22. Gunjal, S., Ankola, A.V. and Bhat, K. (2015) In vitro antibacterial activity of ethanolic extract of Morus alba leaf against periodontal pathogens. Indian J. Dent. Res., 26(5): 533-536.

23. Yiemwattana, I., Chaisomboon, N. and Jamdee, K. (2018) Antibacterial and anti-inflammatory potential of Morus alba stem extract. Open Dent. J., 12(1): 265-274.

24. CLSI. (2016) Methods for Antimicrobial Dilution and Disk Susceptibility Testing of Infrequently Isolated or Fastidious Bacteria. $3^{\text {rd }}$ ed. Clinical and Laboratory Standard Institute, Wayne, PA.
25. Mozin, S., Rosyidi, D., Sjofjan, O. and Widodo, E. (2015) The effect of shallot (Allium ascalonicum L.) by-product as an antibacterial and alternative phytobiotic on characteristics of small intestine of broiler. Livest. Res. Rural. Dev., 27(4): 1-5.

26. Gabriel, A.A., Ha, T.D., Trinity, R. and Saengchan, S. (2018) Piper betle leaf extract inhibits multiple aquatic bacterial pathogens and in vivo Streptococcus agalactiae infection in Nile tilapia. Turk. J. Fish. Aquat. Sci., 18(5): 671-680.

27. Somayeh, D., Mahmoud, B., Reza, M.K. and Mahmoud, R.K. (2017) Phytotherapy in Streptococcus agalactiae: An overview of the medicinal plants effective against Streptococcus agalactiae. J. Clin. Diagn. Res., 11(6): DE01-DE02.

28. Dian, W.H., Rizke, C. and Fajar, W. (2019) Phytochemical Properties and Antibacterial Activity of Ageratum conyzoides, Piper betle, Muntinga calabura and Curcuma domestica against Mastitis Bacteria Isolates. Vol. 247. IOP Conference Series: Earth and Environmental Science.

29. Ramadan, E.M., Abou-Taleb, K.A., Galal, G.F. and AbdelHamid, N.S. (2017) Antibacterial, antibiofilm and antitumor activities of grape and mulberry leaves ethanolic extracts towards bacterial clinical strains. Ann. Agric. Sci., 62(2): 151-159.

30. Amin, M., Montazeri, E.A., Mashhadizadeh, M.A. and Sheikh, A.F. (2009) Characterization of shallot, an antimicrobial extract of Allium ascalonicum. Pak. J. Med. Sci., 25(6): 948-952.

31. Jafari, B. and Ahmadizadeh, C. (2017) The in vitro study of antimicrobial effect of marigold (Calendula officinalis) extract on infectious microorganisms. Electron. J. Biol., 13(4): 348-352.

32. Raabe, V.N. and Shane, A.L. (2019) Group B streptococcus (Streptococcus agalactiae). Microbiol. Spectr., 7(2): 228-238.

33. Carvalho-Castro, G.A., Silva, J.R., Paiva, L.V., Custodio, D.A.C., Moreira, R.O., Mian, G.F., Prado, I.A., Chalfun-Junior, A. and Costa, G.M. (2017) Molecular epidemiology of Streptococcus agalactiae isolated from mastitis in Brazilian dairy herds. Braz. J. Microbiol., 48(3): 551-559. 